\title{
Multilinguales
}

1 | 2013

Pratiques littéraires, linguistiques, pédagogiques,

didactiques et médiations culturelles contemporaines

\section{L'ethnocritique de la littérature : Présentation et situation}

Ethnocriticism of literature: Introduction and Contextualisation

\section{Marie Scarpa}

\section{OpenEdition}

Journals

Édition électronique

URL : https://journals.openedition.org/multilinguales/2808

DOI : $10.4000 /$ multilinguales. 2808

ISSN : 2335-1853

Éditeur

Université Abderrahmane Mira - Bejaia

Édition imprimée

Date de publication : 1 juin 2013

Pagination : 07-18

ISSN : 2335-1535

Référence électronique

Marie Scarpa, «L'ethnocritique de la littérature : Présentation et situation », Multilinguales [En ligne], 1 । 2013, mis en ligne le 01 juin 2013, consulté le 01 juillet 2021. URL : http://journals.openedition.org/ multilinguales/2808; DOI : https://doi.org/10.4000/multilinguales.2808

Ce document a été généré automatiquement le 1 juillet 2021.

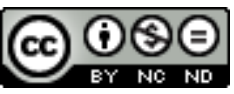

Multilinguales est mise à disposition selon les termes de la Licence Creative Commons Attribution Pas d'Utilisation Commerciale - Pas de Modification 4.0 International 


\title{
L'ethnocritique de la littérature : Présentation et situation
}

\author{
Ethnocriticism of literature: Introduction and Contextualisation
}

Marie Scarpa

1 L'ethnocritique a une vingtaine d'années maintenant ${ }^{1}$. Le mot a été forgé, sur le modèle de "psychocritique », «mythocritique », "sociocritique ", pour désigner une méthode d'analyse littéraire, une lecture interprétative de la littérature qui, pour le dire vite, travaille à articuler poétique du texte et ethnologie du symbolique. Cette démarche s'inscrit plus largement dans un vaste mouvement historique et épistémologique de relecture des biens symboliques. Du côté des sciences sociales et humaines, se sont développées en effet l'histoire du quotidien et la micro-histoire, l'anthropologie des pratiques culturelles (avec les thèses de N. Elias par exemple) et l'ethnologie du proche et du présent voire l'ethnologie de soi et du semblable ${ }^{2}$. Du côté des critiques littéraires, la génétique textuelle, les différents travaux sur la dynamique des genres, la polyphonie langagière et le dialogisme, l'analyse du discours, etc., ont permis de reconsidérer la fameuse « clôture » du texte. Ainsi la voie s'est-elle ouverte pour des lectures, plus anthropologiques, de la littérature.

\section{Ethnologie - littérature / littérature - ethnologie}

2 A dire vrai, les relations ou plus exactement les questionnements réciproques entre anthropologie et littérature existent de longue date. Peut-être pouvons-nous commencer par rappeler, brièvement, quelques-uns des lieux de croisement de ces deux champs disciplinaires.

3 Si l'on place la focale à un niveau très englobant (qui n'est pas le point de vue que nous privilégierons ici), on peut penser la littérature comme anthropologie et s'intéresser alors à ses vérités sur l'humaine condition. Comme l'écrit A. Viala dans la notice «Anthropologie» du Dictionnaire du littéraire: «(...) le rapport de l'anthropologie à la littérature peut s'entendre de deux façons: pour éclairer une conception de l'homme et de ses 
comportements exprimés dans les textes, et pour analyser le littéraire comme une des composantes de l'anthropologie culturelle»(Viala, 2002). Ainsi, pour ne prendre que l'exemple d'une anthropologie générale de l'écrit, on peut citer la pensée d'un théoricien comme Wolfgang Iser qui lie étroitement «les cultures de la tradition écrite " et la "littérature d'imagination", ce qui l'amène à poser la "fiction » (évidemment, il faudrait définir plus précisément ce dernier terme) comme un trait anthropologique fondamental ${ }^{3}$. Un certain nombre d'autres auteurs interrogent d'ailleurs cette capacité qu'a l'être humain à "fictionner " ${ }^{4}$, aptitude qui peut être appréhendée comme une opération cognitive spécifique.

4 Si l'on resserre la focale à un niveau qu'on pourrait nommer "littérature et anthropologie ", d'autres problématiques viennent à l'esprit. Ainsi la littérature a-telle pu d'abord être considérée comme un " document ", comme un " conservatoire des mœurs ", en particulier lorsqu'elle met en scène des périodes où l'ethnologie n'existe pas encore en tant que telle ${ }^{5}$. Puis, quand la discipline se met en place institutionnellement, à la fin du XIXe siècle, et qu'elle se centre sur les sociétés du proche et du présent, dans la foulée des travaux des folkloristes, la littérature dite réaliste peut lui apparaître comme un modèle tant elle semble en avance sur le plan des objets traités comme sur celui de sa « méthode»:

L'étude du monde rural a été pendant longtemps le domaine d'élection de l'ethnologue : issu de la ville, celui-ci négligeait de se pencher sur le milieu même dans lequel il vivait, c'est-à-dire le milieu urbain. L'étude du décor de la rue n'est qu'un des éléments d'une ethnologie urbaine qui a vu le jour au XXe siècle; les romanciers et les chroniqueurs qui se sont penchés sur les aspects quotidiens de la ville peuvent être considérés comme les précurseurs de cette ethnologie ${ }^{6}$.

5 Le romancier, avec Flaubert ou Zola par exemple, se dote en effet d'un véritable « discours de la méthode » qui va concerner aussi bien la délimitation de son objet, sa manière de travailler (documentation, enquête sur le terrain) et son écriture (le cahier des charges » de ce que peut être un style qui veut rendre compte des choses vues et entendues le plus objectivement possible) ${ }^{7}$. Comme l'écrit G. Toffin :

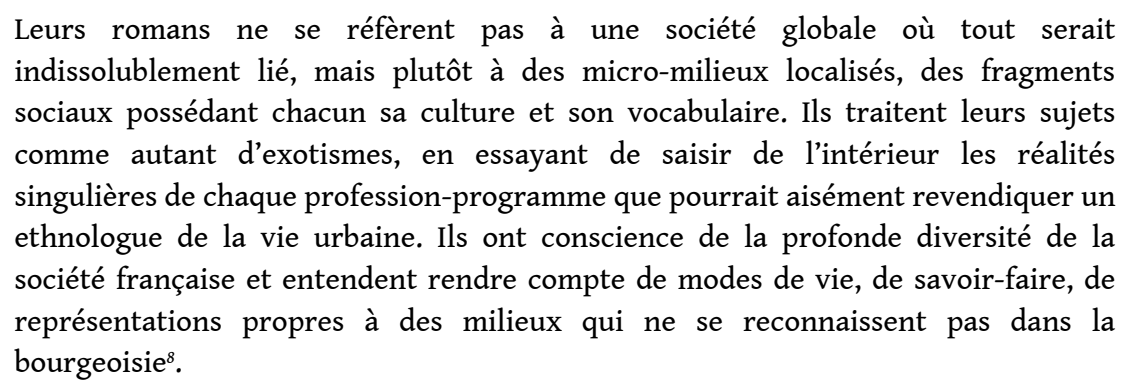

Plus largement, la question de l'écriture (les procédés de restitution comme la description ou la mise en dialogue, la posture de l'énonciateur vis-à-vis du terrain observé et de son énoncé, la contestation du réalisme, etc.) intéresse au plus près l'ethnologue qui doit se la poser lui aussi, de gré ou de force. Et l'on peut dire que cette question n'est pas seulement technique ou utilitaire (comment écrire?), elle touche aussi à l'esthétique. Pensons simplement aux débats qui ont entouré la publication de Tristes Tropiques, manquant de peu le prix Goncourt, et que prolonge d'une certaine manière Barthes lorsqu'il évoque la « tentation ethnologique des grandes cosmogonies romanesques (Balzac, Zola, Proust)", ajoutant aussitôt "réciproquement, de tous les discours savants, l'ethnologique apparaît comme le plus proche d'une fiction $»^{9}$. 
7 Parmi les autres thématiques qui ont pu concerner les folkloristes et les ethnologues, on pourrait penser encore à l'étude des liens entre "littérature orale » (la première occurrence de l'expression est à mettre au crédit d'un écrivain, George Sand) et littérature écrite, ou à celle de la filiation (non chronologique) mythe / conte / roman. Cette dernière, par exemple, a été à plusieurs reprises "travaillée" par de grands anthropologues, Dumézil, Eliade, Lévi-Strauss, etc. On en trouve une autre reformulation, très heuristique pour des littéraires, dans l'essai d'Y. Verdier Coutume et Destin, consacré au romancier Thomas Hardy :

Elle [Y. Verdier] remarque d'abord que trois grandes formes narratives - le mythe, le conte, le roman - préservent une relation forte aux rites qui ordonnancent le temps collectif et lui rapportent le cours de chaque vie, mais cette relation change de nature d'un genre à l'autre. Si l'on retient, avec elle, que les rituels remplissent " une double fonction qui est, d'une part, de représenter les termes et les conditions de l'existence sociale et, d'autre part, de les maintenir tels ", il apparaît que le mythe entretient avec eux un " rapport fondateur ", de façon directe ou détournée il les instaure, il les situe dans la lumière d'une origine ou, du moins, d'une mise en ordre première du monde. Avec les contes le lien ne se distend pas, comme on l'a souvent cru, il se transforme : il ne s'agit plus de remonter à la fondation, mais de donner à entendre "tous les bienfaits que l'on retire à suivre ce que les rites édictent". Le conte est donc toujours, peu ou prou, un récit exemplaire, ses péripéties désignent la bonne voie, semée d'épreuves nécessaires, et qui aboutit toujours à l'achèvement et à l'installation du jeune héros. Et c'est pour cela que les contes finissent bien. Avec le roman, tout change: la coutume et ses rites sont toujours là, mais il nous raconte " ce qui se passe quand on s'en écarte ". (FabreVassas, Fabre, $1995:$ : 30)

8 En réception cette fois, comment ne pas évoquer les problématiques liées aux rôles «culturels» de la littérature: sa place dans les constructions identitaires (régionale, nationale, sociale et... individuelle bien entendu), dans les phénomènes de patrimonialisation, à partir du moment surtout (l'époque romantique grosso modo) où l'on assiste dans les sociétés européennes occidentales au "sacre de l'écrivain », pour reprendre les mots de P. Bénichou, en d'autres termes à un «transfert de sacralité » du champ religieux au champ artistique au sens large ${ }^{10}$ ?

On le voit, le questionnement anthropologique de la littérature est divers et varié (et nous n'avons certes pas tout passé en revue) ; pour autant les relations entre les deux champs n'ont jamais été simples. Comme le rappelle W. Lepenies (1990), au moment où elles vont s'instituer, au tournant des XIXe et XXe siècles, les sciences sociales en quête de légitimation vont rejeter le modèle littéraire, jugé trop peu scientifique. Ainsi, un Van Gennep - qui pourtant a eu maille à partir avec l'académisme et l'académisation ironise sur la dimension ethnographique des romans paysans de George Sand : « G. Sand ne s'est pas donné pour but de décrire des mœurs locales pour elles-mêmes et pour la science: elle n'a vu dans ces mours qu'un canevas où broder des généralisations humanitaires ${ }^{11}$. Et ces tensions perdurent d'une certaine manière à l'époque actuelle. Dans l'Institution (sous toutes ses formes), les ethnologues hésitent à considérer et à revendiquer la littérature comme un véritable «terrain » alors qu'on note dans la pratique un intérêt pour elle qui ne se dément guère ${ }^{12}$.

10 Ce sont, finalement, les critiques littéraires qui vont se saisir de ce dernier aspect pour proposer - et nous sommes là à un troisième niveau - des lectures anthropologiques de la littérature. Des lectures de type interprétatif, visant à une forme d'herméneutique : que l'on pense par exemple à la mythocritique issue des travaux de 
G. Durand ou aux études de R. Girard. C'est ici que l'on pourrait situer l'ethnocritique, même si, bien entendu, les problématiques évoquées aux trois paliers mentionnés interfèrent les unes sur les autres et la concernent d'une façon ou d'une autre.

\section{L'ethnocritique de la littérature}

11 De quelle littérature d'abord traitons- nous? Il ne s'agit justement pas de ce que certains nomment «l'ethnolittérature » et qui serait une sorte d'objet privilégié pour une anthropologie du littéraire: relations de voyages (notamment dans des terres " exotiques»), carnets d'enquête de l'écrivain ou second livre de l'ethnographe, littérature orale, etc. C'est bien la littérature savante, légitime, consacrée qui nous intéresse et qu'il n'est en aucun cas question de considérer comme une sorte de « reflet » à une époque donnée d'une culture donnée. Nous ne cherchons pas non plus à dégager des universaux culturels, qu'il s'agisse par exemple des "grandes structures anthropologiques de l'imaginaire» ou de contenus mythiques expressifs ${ }^{13}$. L'ethnocritique s'emploie plutôt à étudier non pas tant la culture dans le texte que la culture, locale et particulière, $d u$ texte. Plutôt, donc, les variations intraculturelles que les questions d'interculturalité ou les invariants anthropologiques.

Nous faisons l'hypothèse que les traits de culture présents dans l'œuvre littéraire (ce qu'on pourrait nommer des culturèmes) s'organisent en systèmes discursifs et en cosmologies culturelles, toujours métissés et pluriels. Notre objet est donc l'analyse de cette dialogisation, au sein de l'œuvre, d'univers symboliques plus ou moins hétérogènes et hybrides (à savoir les jeux incessants entre culture orale et culture écrite, culture folklorique et culture officielle, populaire et savante, religieuse et profane, féminine et masculine, légitime et illégitime, endogène et exogène, etc.).

On comprend aux termes utilisés ici que l'ethnocritique est née du croisement des recherches sémio-linguistiques de $\mathrm{M}$. Bakhtine ${ }^{14}$ (sur la polyphonie notamment) et des travaux des ethnologues du symbolique (Cl. Lévi-Strauss en premier lieu, puis Y. Verdier et D. Fabre en particulier quand ils s'intéressent au domaine des écrits littéraires).

Nous tentons une cartographie de la culture du texte et de ses dénivellations internes, ce qui introduit bien à une poétique du texte littéraire: "L'ethnocritique analyse la mémoire longue d'une communauté discursive et la productivité culturelle singulière d'une réécriture (littéraire) aux significations propres et nouvelles ${ }^{15}$.

Sans doute ces propos s'éclaireront-ils davantage avec quelques illustrations concrètes. Dans Le Carnaval des Halles, après avoir étudié la question d'un Zola ethnologue (et sociologue aussi) dans Le Ventre de Paris - dans sa construction notamment du quartier des Halles -, nous avons tenté de prolonger les analyses bakhtiniennes de la carnavalisation littéraire. C'est en effet l'ensemble du cycle folklorico-liturgique Carnaval / Carême / Pâques qui nous a semblé pouvoir jouer le rôle de schème structurant, réorchestré dans le roman à des fins propres, tant esthétiques que sociopolitiques. Il n'y a pas de carnaval à proprement parler dans Le Ventre de Paris, mais ce dernier thématise dans sa fiction et problématise jusque dans le grain de sa narration et de sa langue une logique culturelle de type carnavalesque. Au fond, «tout se passe comme si l'écrit [fictionnel ici] jouait dans les sociétés alphabétisées le rôle assumé par les rituels collectifs dans les civilisations orales » (Furet, Ozouf, $1977:$ 364). C'est à la même conclusion que nous avons abouti dans notre étude consacrée au Colonel Chabert de 
Balzac (Privat, Scarpa, 2010: 161-06) ${ }^{16}$. Le récit actualise, on le sait, le retour de nombreux discours de la culture occidentale. On peut évoquer ainsi :

- une interdiscursivité juridique (tout est question de droit ici et de droit à l'identité : le colonel a été déclaré mort officiellement et sa femme s'est remariée à un comte de la Restauration, Ferraud, en héritant des biens de son premier mari) ;

- une interdiscursivité épique (le héros avec son crâne fendu et sa cicatrice spectaculaire n'est pas sans faire penser à Ulysse rentrant à Ithaque après des années d'errance, vieilli, méconnaissable puis retrouvant une nouvelle prestance et se faisant reconnaître d'Eumée et de Pénélope) ;

- une interdiscursivité populaire et folklorique: le motif du retour du mari/soldat disparu est présent dans un certain nombre de contes de la tradition orale ${ }^{17}$, mais aussi dans des chansons folkloriques qui ont été en vogue longtemps ${ }^{18}$;

- une interdiscursivité biblique (pour ne donner qu'un exemple, Balzac avait dans un premier temps intitulé la seconde partie de son récit « La Résurrection »).

thématique du retour est souvent doublée par une autre : ces disparus sont donnés comme "revenant», symboliquement du moins, du " pays des morts ». Le récit de Balzac n'échappe pas à la règle ; il n'est que de lire le premier portrait du colonel :

Le colonel Chabert était [...] parfaitement immobile. Le vieux soldat était sec et maigre [...]. Le visage, pâle, livide, il semblait mort [...]. L'absence de tout mouvement dans le corps, de toute chaleur dans le regard [...] s'accordait pour faire de cette figure je ne sais quoi de funeste qu'aucune parole humaine ne pourrait exprimer. $(60-61)^{19}$

Mais si le schème culturel du retour du mort est très productif dans l'économie symbolique du roman, il est à noter qu'il est traité sur le mode du retournement parodique. La cicatrice d'Ulysse lui permet d'être reconnu, celle de Chabert finit par le rendre méconnaissable et aucune Pénélope ne l'a attendu; son ex-épouse, loin de pleurer et de se désoler comme dans la chanson du soldat disparu, tente de le dépouiller une seconde fois ; sa " résurrection » est suivie d'un chemin de croix (et non l'inverse); son "sacrifice» ne sauve que les coquins et la "société de mensonge». A quoi exactement est imputable l'échec du colonel?

On sait que Balzac condamne les désordres d'une société de la Restauration fonctionnant à l'envers et donnant à l'argent corrupteur (et aux mécanismes libéraux d'une société bourgeoise en pleine expansion) une trop grande place. Mais on peut aller plus loin.

19 Chabert qui se fait parfaitement reconnaître, en réalité, par tous les protagonistes de l'histoire échoue parce qu'il n'a pas les papiers d'identité, soit les documents officiels écrits, qui permettraient de prouver légalement son existence. A contrario, tout son drame tient dans le fait que sa mort, elle, a été déclarée dans un acte de décès " authentique », écrit et publié :

[...] quand je m'élève, moi, mort, contre un acte de décès, un acte de mariage et des actes de naissance, ils [les avoués] m'éconduisent [...]. J'ai été enterré sous des morts, mais maintenant je suis enterré sous des vivants, sous des actes, sous des faits, sous la société tout entière [...]. (74)

Ce que met en scène finement le récit balzacien, c'est le basculement dans un monde gouverné de manière dominante par la "raison graphique " (selon l'expression de J. Goody), au moment de ce que l'anthropologie historique et culturelle a nommé la «mutation graphique ». On connaît la fascination de Balzac pour le monde de la culture écrite, de la « littératie », lui qui établit explicitement une concurrence entre sa Comédie 
humaine et l'Etat civil. Le début du Colonel Chabert dépeint le monde des clercs; le lieu principal et principiel du récit est l'étude de l'avoué, Maître Derville, qui proposera à Chabert de «transiger » par écrit avec la comtesse Ferraud.

21 Notre hypothèse de lecture est donc que l'enjeu du roman de Balzac se situe essentiellement dans le jeu des tensions et des interactions entre culture de l'oralité traditionnelle et modernité de la culture de l'écrit. Le comportement et l'ethos du colonel semblent bien témoigner d'une nostalgie de ce monde ancien caractérisé chez lui par des règles d'hospitalité et de solidarité, de valorisation de l'entre-soi communautaire, par un code d'honneur où la reconnaissance se fait de visu et où le corps et la parole suffisent à témoigner d'une identité. Mais le vieux soldat " revient » dans un monde structuré désormais par la raison littératienne où «ce qui garantit les relations inter-individuelles (...) est la double autorité du marché et de l'Etat, scellée par l'écriture, incarnée par le contrat et la loi » (Furet, Ozouf, 1977: 360). Et le roman va pousser au bout la logique de dépersonnalisation qui s'ensuit: les écrits même faux triomphent de la parole du héros et ce dernier qui finit à l'hospice de la vieillesse de Bicêtre n'est plus qu'un matricule: "Je ne suis plus un homme, je suis le numéro 164, septième salle » (163).

On comprend du même coup à quel point est significatif le fait que le colonel prend dans le roman la figure du revenant. Les morts reviennent rarement sans raison hanter le monde des vivants et le "défunt» Chabert a tout du "mauvais» mort, mort précocement et brutalement, jeté dans la fosse commune sans autre forme de rite ${ }^{20}$. Il est l'un de ces « morts malveillants » qui viennent reprocher à leurs épouses de s'être remariées et de garder pour elles leur fortune. Son retour est une réclamation (du règlement d'une dette) et une dénonciation ( $d$ 'un désordre social).

Tout se passe donc comme si la structure même du récit balzacien était dans une relation d'homologie fonctionnelle avec la logique folklorique d'un processus de type charivarique. De fait, le roman présente un cumul de conditions qui déclenchent habituellement un charivari :

- une femme de mauvaise vie (Rosine Chapotel est une ancienne prostituée) convole impunément en « justes noces»;

- cette femme, devenue veuve et riche, se remarie avec un jeune homme, le comte Ferraud ;

- après le retour de son premier mari, Rosine est bigame ;

- Chabert, le héros de la Grande armée, se révèle vite être un homme dominé par son épouse et un « cocu impuissant », etc.

24 L'avoué Derville a parfaitement compris la situation, lui qui menace un temps de publiciser la situation personnelle et intime de « la comtesse à deux maris » (c'était l'un des premiers titres donnés par Balzac à son récit) et de la faire devenir « la fable de tout Paris ».

25 Mais, au bout du compte, le charivari annoncé, en tant que technique de contrôle social - un contrôle collectif, extériorisé, ritualisé et spectaculaire - échoue face à la logique moderne et bourgeoise du contrôle écrit, personnalisé, secret et confidentiel ${ }^{21}$. 


\section{Enjeux et perspectives ethnocritiques}

Après l'étude du Colonel Chabert, notre hypothèse de travail s'est élargie : l'empire de la "raison graphique " et ses effets, ce que nous appelons la "littératie ${ }^{22}$, à l'ère Gutemberg et à celle du numérique aussi, travaillent puissamment tous les imaginaires langagiers et artistiques. De plus, on l'a vu dans les deux exemples rapidement exposés, nos analyses rencontrent souvent la question des relations entre rite et littérature ou, en tout cas, celle d'une homologie possible, fonctionnelle et structurelle, entre rite et récit. Question qu'il faudrait sans doute systématiser ${ }^{23}$.

Ces deux problématiques nous conduisent à la possibilité de reconsidérer, à cette aune, les genres littéraires, au moins narratifs. Le revenant Chabert incarne littéralement la rupture entre des cosmologies différentes et ces "conflits de cosmologies » seraient précisément, selon le philosophe V. Descombes, le propre du roman moderne. Une cosmologie est une théorie collective du monde, un système culturel finalement :

Proust a accentué les aspects provinciaux, villageois de Françoise, de façon à obtenir un contraste plus saisissant entre ses vues et celles de Marcel, pour qui Combray n'est plus qu'un pays de vacances. Les idées de Françoise sont les idées de Combray. Tant que Combray reste égal à lui-même, les idées collectives ne prennent jamais la forme d'un système articulé dans un livre canonique. C'est pourquoi le romancier doit procéder comme un ethnographe et recueillir les principes cosmologiques de Combray à deux sources : la conversation et le « coutumier ». (...) Il y a, on le voit, un contraste extrême entre la cosmologie des braves gens de Combray et la cosmologie de la vie parisienne. (...) La différence entre Paris et Combray est en fin de compte la suivante: Combray est un monde dont les habitants n'ont pas l'occasion ni peut-être l'idée de s'individualiser ; à Paris et dans la partie parisienne de la famille du narrateur, il est non seulement possible, mais il est même tenu pour légitime de se conduire en individu responsable de soi et du monde dans lequel on entend vivre. (Descombes, 1987 : 179 -187)

Le roman moderne (celui qui émerge peu ou prou dans la seconde moitié du XVIIIe siècle en Occident) articulerait, en partie tout au moins, un "comment vivre ensemble » et les processus d'individuation et de singularisation des personnages. Cette tension (le personnage entre la coutume et son destin, au fond) pourrait permettre - et c'était le sens de la citation d'Y. Verdier donnée plus haut - de repenser la relation mythe / conte / roman.

Certains personnages passeraient donc d'une cosmologie à l'autre ; d'autres, non, qui restent sur les frontières, dans un entre-deux mondes. Nous les appelons des personnages liminaires (Scarpa, 2009).

Les trajectoires des héros de fiction, on le sait, peuvent être lues en termes d'initiation mais nous proposons de donner à la notion une acception plus stricte, qui correspond au processus de socialisation des individus dans leurs apprentissages des différences de sexe, d'état et de statut; processus que matérialise leur plus ou moins grand succès dans les épreuves, dans les rites de passage qu'ils traversent tous.

Certains personnages, donc, ne "passent » pas, ne franchissent pas (ou mal) les seuils et les étapes inhérents à la construction individuelle et sociale de l'identité. Non initiés ou mal initiés - hommes ou femmes « inachevés » culturellement -, ils restent bloqués dans un entre-deux constitutif. Leur ambivalence structurelle (ils ne sont plus ce qu'ils étaient et ne seront jamais ce qu'ils auraient dû être) fait trembler les lignes de partage sur lesquelles se fondent la cosmologie d'un groupe social et qui se jouent précisément 
dans les espaces-temps de la marge où s'explorent les limites entre les vivants et les morts, le masculin et le féminin, le civilisé et le sauvage.

Ces catégories paradigmatiques peuvent se recouper partiellement et produire d'autres relations de symétrie et de dissymétrie (visible / invisible, raison / folie, enfance / état adulte, étranger / autochtone, etc.).

Il va de soi, qu'en fonction des cultures, des récits et des genres, ces couples notionnels sont polarisés (un idiot ou un habile, une femme ou un homme, un enfant ou un adulte, etc., ne sont pas valorisés de la même manière). Dans la mesure où le personnage liminaire fait le détour par l'autre comme tout un chacun mais ne parvient pas à revenir complètement de cette altérité, il est placé souvent, dans le système des normes culturelles, du côté du pôle le moins positif ou le plus problématique. Fréquemment, il est un personnage secondaire, qui sert alors aux autres de valeur ou de contre-valeur témoin.

Mais plus on avance dans le temps de la modernité, plus il est un personnage principal qui, à défaut de passer lui-même, peut faire office de passeur pour les autres.

Parfois, depuis son figement sur les seuils et son rôle dans les médiations, le moins initié peut devenir pour ces raisons mêmes, sur un autre plan, un sur-initié. Dans certains cas même, le non initié sur-initié a tout du trickster qui, transgressant les règles et les frontières, fonde un ordre nouveau.

Pour finir sans en finir, disons que nos perspectives de travail les plus actuelles tentent de s'ancrer davantage encore dans l'étude des polycultures et des polylogies textuelles. Ce sont bien les structures langagières et symboliques des discours littéraires (textes mais avant-textes également, puisque nous pensons possible une ethnogénétique) qui nous intéressent. Faisant nôtre la réflexion de Wittgenstein, "toute une mythologie est inscrite dans le langage ", nous allons jusqu'à parler de la culture de la langue ${ }^{24}$. Si d'aucuns définissent la sociocritique comme une herméneutique sociale de littérature ${ }^{25}$, l'ethnocritique serait plutôt, quant à elle, une herméneutique culturelle de la littérature.

\section{BIBLIOGRAPHIE}

ARON P, SAINT-JACQUES D., VIALA A. éds, Le Dictionnaire du littéraire, Paris, Presses Universitaires de France, 2002.

BAKHTINE M., La Poétique de Dostoïevski, Paris, Seuil, 1970 (1929).

BAKHTINE M., L'Euvre de François Rabelais et la culture populaire au Moyen Âge et sous la Renaissance, Paris, Gallimard, 1970 (1965).

BAKHTINE M., Esthétique et théorie du roman, Paris, Gallimard, 1978 (1975).

BAKHTINE M., Esthétique de la création verbale, Gallimard, 1984 (1979).

CNOCKAERT V., PRIVAT J.M., SCARPA M. éds., L'Ethnocritique de la littérature (Anthologie), Presses de l'Université du Québec, 2011. 
DESCOMBES V., Proust. Philosophie du roman, Paris, Minuit, 1987.

FABRE D., » La Voie des oiseaux. Sur quelques récits d'apprentissage », L’Homme, 99, 1986- XXVI (3), pp. 7-40.

FABRE D., » Carlo Levi au pays du temps », L'Homme, 1990, XXX (2), 114, pp. 50-74.

FABRE D., « La culture paysanne », Burguière A., Revel J., Histoire de La France. Les Formes de la culture, Paris, Seuil, 1993, pp. 123-224.

FABRE D., « Le corps pathétique de l'écrivain », Gradhiva, 1999, 25, pp. 1-13.

FABRE-VASSAS Cl., FABRE D., » Du rite au roman. Parcours d'Yvonne Verdier », Y. Verdier, Coutume et destin, Paris, Gallimard, 1995, pp. 7-37.

FURET F., OZOUF J., Lire et écrire. L'alphabétisation des Français de Calvin à Jules Ferry, vol. 1, Paris, Minuit, 1977.

KARA M., PRIVAT J.M. éds., Pratiques, 131-132, La Littératie. Autour de Jack Goody, 2006.

LEPENIES W., Les Trois cultures. Entre science et littérature, l'avènement de la sociologie, Paris, Editions de la maison des sciences de l'homme, 1990.

LEVI-STRAUSS Cl., Introduction à l'œuvre de Marcel Mauss, M. Mauss, Sociologie et anthropologie, Paris, P.U.F., 1997 (1950), pp. IX-LII.

LEVI-STRAUSS Cl., Anthropologie structurale, Paris, I et II, Plon, 1958 et 1974.

PRIVAT J.-M., Bovary Charivari, Paris, CNRS Editions, Coll. Littérature, 1994, (réimp. 2002).

PRIVAT J.-M., « Ethnocritique et lecture littéraire », J.L. Dufays, L. Gemenne et D. Ledur dir., Pour une lecture littéraire, 2, Bilan et confrontation, Bruxelles, De Boeck-Duculot, 1996, pp. 76-82.

PRIVAT J.-M., SCARPA M. éds., Horizons ethnocritiques, Postface de Ph. Hamon, Presses universitaires de Nancy, collection EthnocritiqueS, 2010.

PRIVAT J.-M., SCARPA M. éds., Anthropologies de la littérature, Pratiques, 151-152, décembre 2011.

PRIVAT J.-M., SCARPA M. éds., Romantisme, L'ethnocritique de la littérature, 2009-3, 145.

SCARPA M., Le Carnaval des Halles. Une ethnocritique du Ventre de Paris de Zola, Paris, CNRS Editions, Coll. Littérature, 2000.

SCARPA M., «Les poissons rouges sont-ils solubles dans le réalisme ? Lecture ethnocritique d'un " détail " du Ventre de Paris ", Poétique, 133, 2003, pp. 61-72.

SCARPA M., L'Eternelle jeune fille. Une ethnocritique du Rêve de Zola, Paris, Honoré Champion, 276 p., 2009.

SCARPA M., « Le personnage liminaire », Romantisme, L'ethnocritique de la littérature, 2009-3, 145, pp. 25-35.

VERDIER Y., Façons de dire, façons de faire, Paris, Gallimard, 1979.

VERDIER Y., Coutume et destin. Thomas Hardy et autres essais, Paris, Gallimard, 1995.

\section{NOTES}

1. Cet article est une version remaniée d'une contribution à paraître dans Actualités de la sociocritique, P. Popovic et P. Maurus éds., Paris, L'Harmattan, 2013. Le terme " ethnocritique» 
apparaît en 1988 dans un article consacré à Madame Bovary par J.-M. Privat. Mais c'est la publication de l'essai de ce dernier, Bovary Charivari, chez CNRS Editions en 1994, qui lance véritablement la démarche. On trouvera sur le site www.ethnocritique.com une bibliographie exhaustive.

2. Voir par exemple, les ouvrages collectifs L'Autre et le semblable, M. Segalen dir., Paris, Presses du CNRS, 1989, pp. 19-33 et Vers une ethnologie du présent, G. Althabe, D. Fabre, G. Lenclud dir., Paris, Ed. MSH-Paris, Collection Ethnologie de la France, Cahier 7, 1992, pp. 9-37. L'idée qu'on peut faire une ethnologie de soi - et pas seulement d'autrui - est au cœur de la démarche ethnocritique.

3. W. Iser, Das Fiktive und das Imaginare. Perspektiven literarischer Anthropologie, Frankfurt a. M., 1991.

4. C'est dans ce sens que s'orientent par exemple les travaux de J.-M. Schaeffer, depuis Pourquoi la fiction?, Paris, Seuil, 1999. On peut penser aussi à J. Bruner, Pourquoi nous racontons-nous des histoires?, Paris, Retz, 2002.

5. Nombreux en effet sont les professionnels des sciences humaines et sociales qui se sont servis de la littérature comme d'un document : souvent, de certains modes de vie, lieux ou pratiques, il ne reste que des descriptions littéraires. Ainsi, par exemple, l'appendice de La Mare au Diable de G. Sand peut-il témoigner assez vraisemblablement de ce qu'ont pu être au début du XIXe siècle une noce berrichonne et un rite comme celui du « chou ». Cette question revêt toujours une certaine actualité : ainsi du côté des sociologues, on peut citer à titre d'exemple une conférence de $\mathrm{N}$. Heinich à l'Ecole Normale Supérieure de la rue d'Ulm en janvier 2004 intitulée «La littérature comme document pour le sociologue »; du côté des historiens, voir le livre récent de J. Lyon-Caen et D. Ribard, L'Historien et la littérature, Paris, La Découverte, 2010.

6. J. Chamarat, C. Reinharez, «La ville, ses rues, ses boutiques", Hier pour demain. Arts, Traditions et Patrimoine, Paris, Musée National des Arts et Traditions Populaires, Editions de la Réunion des musées nationaux, 1980, p. 217.

7. On peut rappeler, à titre d'exemple, que les Carnets d'enquêtes de Zola, publiés en 1986 par H. Mitterand dans une collection importante pour l'ethnologie, la collection « Terre humaine » chez Plon, portent le sous-titre suivant: Une ethnographie inédite de la France. J. Malaurie en signe la préface et écrit : "Cet écrivain est, en France, l'un de ceux qui a le mieux fait percevoir l'importance de l'environnement physique et des structures sociales pour la germination d'une pensée ». Pour toutes ces raisons, au début du XXe siècle, le roman réaliste a pu être pris comme modèle scriptural et générique de la monographie ethnographique.

8. G. Toffin, « Ecriture romanesque et écriture de l'ethnologie ", L'Homme, 111-112, 1989, p. 36.

9. R. Barthes, Roland Barthes par Roland Barthes, Paris, Seuil, Coll. "Les Ecrivains de toujours ", 1975, p. 87. Voir aussi sur la question V. Debaene, L'Adieu au voyage. L'ethnologie française entre science et littérature, Paris, Gallimard, Bibliothèque des Sciences humaines, 2010.

10. P. Benichou, Le Sacre de l'écrivain 1750-1830. Essai sur l'avènement d'un pouvoir spirituel laïque dans la France moderne, Paris, J. Corti, 1973.

11. A. Van Gennep, «G. Sand folkloriste », Le Mercure de France, 1926.

12. Il suffit par exemple de considérer, ces dernières années, la liste des séminaires d'anthropologie proposés à l'Ecole des Hautes Etudes en Sciences Sociales (à Paris). Voir par exemple en 2006-2007, le séminaire d'A. Bensa et F. Pouillon, « Les grands écrivains sur le terrain de l'ethnographie », ou celui de J.P. Colleyn et J. Jamin, « Anthropologie, image et littérature », et celui de D. Fabre, « Le paradigme des derniers », pour l'année 2009-2010.

13. En somme, l'ethnocritique n'est ni une folkloristique ni une anthropocritique (ou mythocritique). Pour une première réflexion sur les différences qu'il nous semble voir entre ces approches anthropologiques de la littérature, voir M. Scarpa, Le Carnaval des Halles, Conclusion, op. cit., p. 265-272. L'ethnocritique est-elle une branche des Cultural studies? On pourrait dire que l'ethnocritique est bien une " étude culturelle » de la littérature, mais à regarder les travaux des 
Cultural Studies les différences sont assez évidentes. La génération des fondateurs anglais (R. Hoggart, E.T. Thompson notamment) nous a beaucoup appris, puisqu'elle s'est intéressée à la culture populaire (comme culture du peuple et comme culture de masse), mais si elle a renouvelé la sociologie de la réception (ce qui nous importe évidemment), son sujet n'est en aucun cas l'interprétation de la littérature. Chez leurs continuateurs, américains surtout, l'approche culturaliste a fait la part belle aux nouveaux objets de la culture de masse (médias audio-visuels, cyber-œuvres, etc.) et dans les œuvres littéraires, aux cultures dites " minoritaires » (féministes, ethniques, homosexuelles, etc.). Si nous avons sans doute certains principes communs (en premier lieu la conviction que le rapport à l'œuvre d'art doit être « reculturé » et que, pour ce faire, il faut à la fois tenir compte et nuancer les théories de la domination symbolique), nous avouons ne pas voir vraiment d'autre convergence avec l'ethnocritique (mais le champ des Cultural Studies est immense et ce que nous pouvons en connaître sans doute très limité).

14. M. Bakhtine écrit ainsi dans "Les études littéraires aujourd'hui ", Esthétique de la création verbale, Paris, Gallimard, NRF, Bibliothèque des Idées, 1979, pp.339-348: "La science de la littérature se doit, avant tout, de resserrer son lien avec l'histoire de la culture. La littérature fait indissolublement partie de la culture [...]. L'action intense qu'exerce la culture (principalement celle des couches profondes, populaires) et qui détermine l'œuvre d'un écrivain est restée inexplorée et, souvent, totalement insoupçonnée ».

15. J.-M. Privat, "Le Retour et ses discours ", Sciences du texte et analyse de discours. Enjeux d'une interdisciplinarité, J.-M. Adam et U. Heidmann éds, Études de Lettres, Lausanne, 1-2, 2005, p. 197.

16. Nous citons le roman de Balzac dans l'édition de P. Berthier chez Gallimard, collection Folio classique, 1999.

17. Voir par exemple les contes «La Quête de l'époux disparu » (T 425), « La Fille du Diable» (T 313), «L'Homme à la recherche de son épouse disparue » ( $\mathrm{T} 400)$ et «La Princesse délivrée après trois nuits d'épreuves».

18. Voir G. Doncieux, Romancéro populaire de la France, XXXVI, pp. 407- 416.

19. Du reste, Chabert est littéralement sorti de la « fosse des morts " : "J'entendis ou crus entendre [...] des gémissements poussés par le monde de cadavres au milieu duquel je gisais [...]. Il y a des nuits où je crois encore entendre ces soupirs étouffés! Mais il y a quelque chose de plus horrible que les cris, un silence que je n'ai jamais retrouvé nulle part, le vrai silence du tombeau » (68).

20. Les morts avant l'heure sont condamnés à être des «errants perpétuels, tantôt agressifs, tantôt seulement envieux. Ils reviennent parce qu'il leur manque l'essentiel : les gestes et les mots qui accomplissent le passage » (A. Fine, « Le Parrain, son filleul et l'au-delà », Etudes rurales, Le Retour des morts, 105-106, 1987, p. 139). Voir aussi, entre autres, sur cette question, Cl. LéviStrauss, » La visite des âmes ", Paroles données, Paris, Plon, 1984, pp. 245-248.

21. Sur le charivari, nombreux sont les ouvrages ou les articles de référence; ne citons ici que D. Fabre, «Le privé contre la coutume », Histoire de la vie privée, P. Ariès et G. Duby dir., Paris, Seuil, 1999, tome 3, pp. 530-531.

22. J.-M. Privat définit la littératie comme l'ensemble des praxis et représentations liées à l'écrit, depuis les conditions matérielles de sa réalisation effective (supports et outils techniques d'inscription) jusqu'aux objets intellectuels de sa production et aux habiletés cognitives et culturelles de sa réception, sans oublier les agents et institutions de sa conservation et de sa transmission. La littératie s'oppose ainsi à l'oralité comme la culture écrite à la culture orale. Il va de soi que les interférences entre l'une et l'autre sont incessantes et de fait constitutives des cultures modernes et contemporaines (Kara, Privat, 2006).

23. On trouvera les prémices de cette réflexion dans nos différents travaux, en particulier dans le chapitre IV de M. Scarpa, L'éternelle jeune fille. Une ethnocritique du Rêve de Zola, Paris, Honoré Champion, 2009.

24. L. Wittgenstein, Remarques sur Le Rameau d'or de Frazer, Lausanne, L'Age d'Homme, 1982 (1930-32). 
25. P. Popovic, «La sociocritique. Définition, histoire, concepts, voies d'avenir », Pratiques, 151-152, pp. 7-38.

\section{RÉSUMÉS}

Cette contribution se propose d'abord de situer l'ethnocritique de la littérature dans l'ensemble complexe des rapports qu'entretiennent littérature et anthropologie, puis dans ses relations de voisinage théorique avec des disciplines critiques connexes. Elle revient aussi sur la définition la plus actuelle de cette méthode nouvelle d'analyse littéraire, ses enjeux et ses problématiques (en particulier l'homologie rite/récit, les interactions croisées entre oralités et littératies, la question du personnage liminaire).

This article situates the ethnocriticism of literature first of all in the perspective of the complex relations between literature and anthropology, then from the point of view of its proximity to other closely-related critical fields. It also proposes an updated definition of this new method of literary analysis, its objectives and themes (notably the homology between ritual and narrative, the complex interactions between forms of orality and literacy, the question of liminal characters).

\section{INDEX}

Mots-clés : Littérature, ethnocritique, anthropologie, analyse littéraire, pratique symbolique Keywords : Literature, ethnocriticism, anthropology, literature theory, symbolical practices

\section{AUTEUR}

MARIE SCARPA

Université de Lorraine - CREM 